\title{
Disequilibrium Dynamics in a Simple Macroeconomic Model
}

\author{
VOLKER BÖHM \\ Center for Operations Research \& Econometrics, Université Catholique de Louvain. \\ 34 Voie du Roman Pays, B-1348 Louvain-La-Neuve, Belgium
}

Received January 26, 1977; revised July 8, 1977

\begin{abstract}
The dynamic behavior of a simple macroeconomic disequilibrium model is analyzed in which consumers' changes in money holdings constitute the dynamic link between any two periods. It is shown that, under constant government consumption, a constant production function (no investment), and fixed prices and wages, stationary states of Keynesian unemployment are stable whereas those of repressed inflation are globally unstable. Possibilities of unemployment and output cycles are indicated for fixed wages as well as for some very simple class of wage and price adjustment mechanisms.
\end{abstract}

\section{INTRODUCTION}

Disequilibrium phenomena in dynamic economic models have been treated until recently largely in two separate areas of economic theory. On the one hand, models in the Walrasian tradition treated exclusively price adjustment processes of the tâtonnement type where prices in all markets respond to excess demand. Actual trade in these models is delayed until the equilibrium price system is reached. No information or insight into the dynamic development of other economic variables becomes available. The few existing models of the nontâtonnement type where actual trade occurs at disequilibrium prices do not seem to have increased the understanding of typical disequilibrium phenomena like, for example, unemployment or inflation. On the other hand, following the tradition of business cycle theory, income-expenditure models have in almost all cases ignored price and wealth effects in their analysis. Most of these models use a large list of ad hoo assumptions about the behavior of economic agents which lack a rigorous microeconomic foundation in most cases. Although both models have increased our understanding of some dynamic phenomena, their general results cannot be considered to have increased our understanding of disequilibrium situations.

Two major innovations in economic model building have recently revealed important insights into the structure of short run disequilibrium. phenomena. If combined appropriately they may help to solve many of the 
problems which had to remain unsolved in all previous approaches. One of these innovations consists of a rigorous treatment of the important and wellknown feature that at any state of disequilibrium rationing on some markets due to excess demand or excess supply will have effects on other markets. This will normally lead to a revision of plans of all agents concerned and thus to different trades than those planned for the other markets, even if excess demands there were zero before. Hence, the concepts of notional (Walrasian) demand and supply lose their trade determining significance. This has led to the formulation of models with quantity rationing describing the concepts of constrained demands and supplies. The second innovation constitutes a major contribution to the understanding of the role of money in an intertemporal model where future prices are uncertain and where future markets for commodities do not exist. Under such circumstances expectations about future prices and the possibility to transfer money from one period to the next determine in a natural way the demand for money of any agent with intertemporal preferences. Thus, the effects of money balances as well as of prices on consumption and production decisions can be analyzed. Moreover, even if all other economic parameters, e.g., prices, expectations, etc., remain unchanged from one period to the next, the savings decision creates the dynamic link between any two periods. Unless a stationary state has been reached this change in money holdings will have important effects on the resulting trades in all following periods. A full understanding of these intrinsic dynamic elements is fundamental for a general appreciation of any dynamic model in general.

The model presented here analyzes the dynamic behavior of a simple macroeconomic system where the change in money balances constitutes the major link between any two subsequent periods. We establish the dynamic features under the two different disequilibrium situations which have been called Keynesian unemployment and repressed inflation in models where prices are fixed in any period and trades are determined through quantity rationing. It will be shown that the Keynesian situation is globally stable whereas the inflationary is not, if all prices and wages remain fixed. Sequences of Keynesian equilibria, on the other hand, though generally monotonically converging to a stationary state, may also show cyclical behavior. Thus, an employment and an output cycle is obtained. Moreover, it will be shown that for any "simple" price adjustment mechanism of the Walrasian type, the system tends to be either globally unstable or cyclical, except on a "small" set of initial states. Our results confirm with some modifications the general presumption of global and monotonic stability of income-expenditure models under Keynesian unemployment. On the other hand, they seem to indicate a general instability of Walrasian equilibria, even if these are stationary, and a persistence of disequilibrium, an argument which has been put forward recently in a different context (see Varian [14]). 


\section{EFFECTIVE DeMAND AND SUPPLY}

The basic model used here is an aggregative and simplified version of Grandmont and Laroque [10] with completely fixed prices and wages for any given period. Most of the comparative statics properties of such models were discussed along with other basic issues in Barro and Grossnian [2], Dixit [6], and Malinvaud [13]. Our diagrammatic representation will in some parts be similar to the one given by Barro and Grossman.

A consumption good, labor, and money are the only three commodities in the economy. Consumers are concerned with two periods. Trade is carried out at fixed prices in each period with no possibility of future contracts. Since prices in the subsequent period are unknown consumers form subjective expectations on prices in the next period which are assumed to be held with certainty and independent of currently observed rationing. Money serves as the only store of value to be carried over from one period to the next. Market clearing is achieved by quantity rationing on the long side of each market. Given these data consumers will decide on an optimal consumption plan for the current period given prices and wages, their initial money holdings, expectations, and the possible rationing levels on either market. For our simple model here, this implies that in case of unemployment consumers express their effective consumption demand, and in case of general excess demand for goods they express their effective labor supply.

Let $M_{t}$ denote total real balances at the beginning of period $t$ and let $W_{i}$ denote real wages in period $t$. If rationing on the labor market occurs at an aggregate level $L$, aggregate effective consumption demand will be a function of $M_{t}, W_{t}$, and of $L$. Let $X_{u}=C_{u}\left(M_{t}, W_{t}, L\right)$ denote effective consumption demand. Symmetrically, if rationing occurs on the commodity market at a level $X$, then effective labor supply will be a function $A_{x}\left(M_{t}, W_{t}, X\right)$. According to the underlying utility maximization for the construction of these two functions, there exist $X^{*}\left(M_{t}, W_{t}\right)$ and $L^{*}\left(M_{t}, W_{t}\right)$ such that

$$
A_{x}\left(M_{t}, W_{t}, X^{*}\left(M_{t}, W_{t}\right)\right)=L^{*}\left(M_{t}, W_{t}\right)
$$

and

$$
C_{u t}\left(M_{i}, W_{t}, L^{*}\left(M_{t}, W_{t}\right)\right)=X^{*}\left(M_{t}, W_{t}\right)
$$

Furthermore, $L \geqslant L^{*}\left(M_{t}, W_{t}\right)$ implies

$$
C_{u}\left(M_{t}, W_{t}, L\right)=X^{*}\left(M_{t}, W_{t}\right)
$$

and $X \geqslant X^{*}\left(M_{t}, W_{t}\right)$ implies

$$
A_{x}\left(M_{t}, W_{t}, X\right)=L^{*}\left(M_{i}, W_{t}\right) .
$$


$L^{*}\left(M_{t}, W_{t}\right)$ and $X^{*}\left(M_{t}, W_{t}\right)$ represent unconstrained labor supply and consumption demand, respectively. We will assume throughout that all functions are continuously differentiable in their respective domains. In addition the following more specific assumptions will be made.

(C1) For all $M_{t} \geqslant 0, W_{i} \geqslant 0, L \geqslant 0$

(i) $C_{u}\left(M_{t}, W_{t}, L\right) \geqslant 0$,

(ii) $C_{u}\left(0, W_{t}, 0\right)-0$,

(iii) $\partial C_{u} / \partial M_{t}>0, \quad \partial C_{u} / \partial W_{t}>0, \quad \partial C_{u} / \partial L>0$.

(C2) For all $M_{t} \geqslant 0, W_{t} \geqslant 0, X \geqslant 0$

(i) $A_{x}\left(M_{t}, W_{t}, X\right)>0 \quad$ if $W_{t}>0$,

(ii) $\quad \partial A_{x} / \partial M_{t}<0, \quad \partial A_{x} / \partial W_{t}>0, \quad \partial A_{x /} / \partial X>0$.

(C3) For all $M_{t}>0, W_{t}>0$

(i) $X^{*}\left(M_{t}, W_{t}\right)>0$ and $L^{*}\left(M_{t}, W_{t}\right)>0$,

(ii) $\partial X^{*} / \partial M_{t}>0, \quad \partial X^{*} / \partial W_{i}>0$,

(iii) $\partial L^{*} / \partial M_{t}<0, \quad \partial L^{*} / \partial W_{t}>0$.

A few remarks about these assumptions are in order. An increase in money balances increases consumption demand and decreases labor supply. This implies that both the commodity and leisure are normal goods. On the other hand a positively sloped labor supply curve with respect to the real wage requires that the substitution effect in labor dominates the income effect. The fact that these effects preserve the sign under rationing is suggested by the Le Chatelier-Samuelson principle which also implies that the real wage effect is smaller under rationing than without. Finally, the positive slope of effective consumption with respect to employment is equivalent to a positive marginal (real) propensity to consume. Similarly, the positive slope of effective labor supply with respect to commodity rationing reflects a positive marginal willingness to work. These assumptions are fairly standard on the individual level and have been used widely elsewhere (see, for example, Barro and Grossman [2], Dixit [7], Malinvaud [13]). They can be deduced for the aggregate levei with appropriate assumptions on initial money hoidings and on the rationing mechanism.

A more restrictive element of these assumptions, however, is the neglect of distributional effects of money balances which, in general, play an important role in the determination of effective demand and supply. (For some more explicit analysis of distributional aspects, see Dehez and Jaskold Gabszewicz [5] and Hildenbrand and Hildenbrand [12].) 
The production sector is characterized by a twice continuously differentiable, strictly increasing, atemporal production function $Y=f(L)$ relating current labor input $L$ to current output $Y$. In this simple framework no storage will be possible and an intertemporal reasoning for expected profits will play no role. Therefore, there is no need for producers to hold money. Unconstrained profit maximization in the current period determines output $Y^{*}\left(W_{t}\right)$ and labor demand $Z^{*}\left(W_{t}\right)$ as

$$
f^{\prime}\left(Z^{*}\left(W_{t}\right)\right)=W_{t}
$$

and

$$
Y^{*}\left(W_{t}\right)=f\left(Z^{*}\left(W_{t}\right)\right)
$$

In case of rationing for the producer on the goods market at a level $Y$, his effective labor demand $L_{Y}\left(W_{t}, Y\right)$ is determined by

$$
L_{Y}\left(W_{t}, Y\right)=f^{-1}(Y), \quad Y \leqslant Y^{*}\left(W_{t}\right),
$$

Similarly, his effective supply $Y_{L}\left(W_{t}, L\right)$ in case of rationing on the labor market is determined by

$$
Y_{L}\left(W_{t}, L\right)=f(L), \quad L \leqslant Z^{*}\left(W_{t}\right)
$$

The function $f$ has the additional properties:

(i) $f(0)=0, \quad \lim _{L \rightarrow \infty} f(L)=\infty$,

(ii) $f^{\prime}(0)=\infty$,

(iii) $f^{\prime}>0, \quad f^{\prime \prime}<0$.

Apart from concavity of $f,(\mathrm{P})$ implies that, for all positive real wages, labor demand $Z^{*}\left(W_{t}\right)$ is always positive and that for any feasible state of the producer profits remain nonnegative.

As the third sector in the economy we introduce the government which plays the role of a passive consumer with some fixed strictly positive demand $g$ for commodities and that of a financial clearing house between consumers and producers. It is assumed that government demand is financed by profits and, if necessary, by deficit spending. Therefore, at any feasible state of the economy, at which the government is not rationed in its demand, the wellknown equality of government expenditure with the sum of savings and profits obtains. 


\section{Equilibria ANd Disequilibria}

Given any initial situation $\left(M_{t}, W_{t}\right)$, seven distinct possible cases of equilibria and disequilibria may occur depending on an equal number of market clearing conditions in this economy.

(1) Walrasian temporary equilibrium (WE).

In this case no rationing occurs on either market, i.e.,

$$
X^{*}\left(M_{t}, W_{t}\right)=f\left(Z^{*}\left(W_{t}\right)\right)-g
$$

and

$$
L^{*}\left(M_{t}, W_{t}\right)=Z^{*}\left(W_{t}\right)
$$

(2) Unconstrained demand and supply of consumers and rationing of the production sector on the labor market, i.e.,

$$
X^{*}\left(M_{t}, W_{t}\right)=f\left(L^{*}\left(M_{t}, W_{t}\right)\right)-g
$$

and

$$
L^{*}\left(M_{t}, W_{t}\right)=f^{-1}\left(X^{*}\left(M_{t}, W_{t}\right)+g\right)
$$

with

$$
L^{*}\left(M_{t}, W_{t}\right)<Z^{*}\left(W_{t}\right)
$$

In this case producers realize their effective supply of goods, but production occurs at a level where the marginal product of labor exceeds the real wage.

(3) Unconstrained demand and supply of producers and unemployment for consumers, i.e.,

$$
C_{u}\left(M_{t}, W_{t}, Z^{*}\left(W_{t}\right)\right)=f\left(Z^{*}\left(W_{t}\right)\right)-g
$$

and

$$
L^{*}\left(M_{t}, W_{t}\right)>Z^{*}\left(W_{t}\right)
$$

(4) Unconstrained demand and supply of producers and excess demand of consumers, i.e.,

$$
A_{x}\left(M_{t}, W_{t}, f\left(Z^{*}\left(W_{t}\right)\right)-g\right)=Z^{*}\left(W_{t}\right)
$$

and

$$
X^{*}\left(M_{t}, W_{t}\right)>f\left(Z^{*}\left(W_{t}\right)\right)-g
$$


In all of these four cases at most one sector is in disequilibrium and rationing occurs in one market only. These have to be considered as borderline cases between the following three which describe the true disequilibrium situations.

(5) General excess supply or Keynesian disequilibrium (K).

Such a disequilibrium is defined by a solution $L$ of the set of inequalities and of the equation given by

$$
\begin{aligned}
C_{u}\left(M_{t}, W_{t}, L\right) & =f(L)-g, \\
L<Z^{*}\left(W_{t}\right), \quad L & <L^{*}\left(M_{t}, W_{t}\right) .
\end{aligned}
$$

Equivalently, a pair $(Y, L)$ is a Keynesian disequilibrium if it satisfies effective consumption demand and effective labor demand, i.e.,

$$
C_{u}\left(M_{t}, W_{t}, L\right)=Y-g
$$

and

$$
L_{Y}\left(W_{t}, Y\right)=L
$$

(6) General excess demand or repressed inflation disequilibrium (I).

The disequilibrium is defined by a solution $L$ of

$$
A_{x}\left(M_{t}, W_{t}, f(L)-g\right)=L
$$

and

$$
L<Z^{*}\left(W_{t}\right), \quad X^{*}\left(M_{t}, W_{t}\right)>f(L)-g \text { 。 }
$$

As before, an equivalent form is given by a solution $(Y, L)$ such that

$$
A_{x}\left(M_{t}, W_{t}, Y-g\right)=L
$$

and

$$
Y_{L}\left(W_{t}, L\right)=Y
$$

(7) Unconstrained demand and supply of producers with unemploy ment and excess demand for goods (classical disequilibrium (C)).

This is defined by a solution

$$
L=Z^{*}\left(W_{t}\right)
$$


with

$$
C_{u}\left(M_{t}, W_{t}, L\right)>f(L)-g
$$

and

$$
A_{\infty}\left(M_{t}, W_{t}, f(L)-g\right)>Z^{*}\left(W_{t}\right)
$$

Figures 1 and 2 depict in $(X, L)$-space two typical disequilibrium situations which may arise for alternative $\left(M_{t}, W_{t}\right)$. The Keynesian solution is given by the coordinates $(\bar{L}, \bar{X})$ of Fig. $1 .(\bar{L}, \bar{X})$ of Fig. 2 indicate the solution of repressed inflation. The other five possible cases can easily be visualized

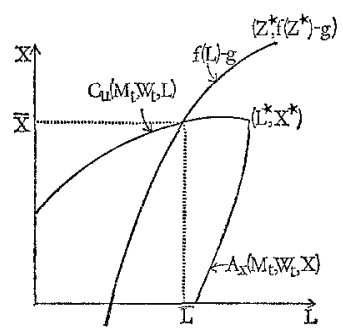

FIGURE 1

using this diagram. It should be noted, however, that no clear conclusion can be drawn on the type of disequilibrium which will result from a simple comparison of the Walrasian demand and supply levels of the two sectors. For example, $\left(L^{*}, X^{*}\right) \ll\left(Z^{*}, f\left(Z^{*}\right)-g\right)$ may result in either one of the

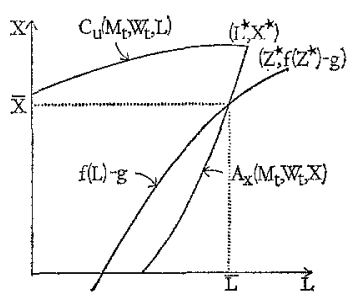

FIGURE 2

two typical disequilibrium situations, Keynesian, or inflationary. Furthermore, given our monotonicity assumptions of $C_{u}$ in $L$ and of $A_{x}$ in $X$, any state other than the Walrasian equilibrium will show a lower level of employment and a lower level of output than at the Walrasian equilibrium. Hence excess demand in the goods market does not guarantee employment of all labor willing to work at the given wage rate. Moreover, the marginal 
product of labor will be higher than the wage rate at all Keynesian and inflationary states.

For the subsequent analysis, in particular for a description of the dynamic development of this economy it is indispensable that at most one of these possible cases occurs for any arbitrary initial position $\left(M_{t}, W_{t}\right)$. The rest of this section will therefore be devoted to the statement and proof of a general uniqueness theorem. To achieve this result the following additional assumption is required.
(A) For any $\left(M_{t}, W_{t}\right)$
(i) $A_{x}\left(M_{t}, W_{t}, 0\right)>f^{-1}(g) \quad$ with $g>0$,
(ii) $\frac{\partial C_{t b}}{\partial L}\left(M_{t}, W_{t}, L\right)<f^{\prime}(L)$ for all $0<L \leqslant Z^{*}\left(W_{t}\right)$,
(iii) $\frac{\partial A_{x}}{\partial X}\left(M_{t}, W_{i}, X\right)<\frac{1}{f^{\prime}(L)}$

for all $X$ and $L$ satisfying $X=f(L)-g$.

Assumption (A) involves elements of both the consumption as well as of the production side. For a uniqueness theorem this seems to be an indispensable procedure. Part (i) indicates that the amount of labor necessary to produce the quantity of commodities demanded by the government is always smaller than the actual labor supplied even under the most severe rationing of consumers. This makes it possible to describe disequilibrium states in which the government is never rationed. Part (ii) guarantees a "normal" multiplier. A stronger but more intuitive assumption would be that the marginal propensity to consume $\left(\partial C_{u} / \partial L\right)\left(1 / W_{t}\right)$ is less than one (see, for example, Hildenbrand and Hildenbrand [12]). Part (iii) is the counterpart of (ii) for the case of repressed inflation. It guarantees a "normal" supply multiplier.

THEOREM. Let $\bar{W}=f^{\prime}(L)$ where $f(L)=g$. If $(\mathrm{A}),(\mathrm{Cl})-(\mathrm{C} 3)$, and $(\mathrm{P})$ hold, then, for any $\left(M_{t}, W_{t}\right)$ with $M_{t} \geqslant 0$ and $0 \leqslant W_{t} \leqslant \bar{W}$, there exists one and only one of the seven possible disequilibrium situations.

Proof. Let $K: R_{+} \rightarrow R$ and $I: R_{+} \rightarrow R$ denote the following two functions.

$$
K(L)=C_{u}\left(M_{t}, W_{t}, L\right)-f(L)+g
$$

and

$$
\begin{aligned}
I(L) & =f(L)-2 f\left(A_{x}\left(M_{t}, W_{t}, 0\right)\right)+g & & \text { if } 0 \leqslant L \leqslant A_{x}\left(M_{t}, W_{t}, 0\right) \\
& =A^{-1}\left(M_{t}, W_{t}, L\right)-f(L)+g & & \text { if } L \geqslant A_{m}\left(M_{t}, W_{t}, 0\right) .
\end{aligned}
$$


One can easily verify that $K(0)>0, I(0)<0$. For $L<L^{*}\left(M_{t}, W_{t}\right)$ one has $K(L)>I(L)$, and for $L \geqslant L^{*}\left(M_{t}, W_{l}\right), K(L)=I(L)$. Furthermore, $K$ is strictly decreasing and $I$ is strictly increasing for all $L \leqslant L^{*}\left(M_{t}, W_{t}\right)$. Hence at least one of the functions must have a zero for $L \in\left[0, L^{*}\left(M_{t}, W_{t}\right)\right]$. If they both have one then they occur at $L^{*}\left(M_{t}, W_{t}\right)$. Otherwise at most one has a zero in $\left[0, L^{*}\left(M_{t}, W_{t}\right)\right]$. One can now directly verify the following seven mutually exclusive cases which correspond to the seven different disequilibrium situations defined above where the same numbering has been used. Except for case (7) all zeroes $\bar{L}$ of either $K(L)$ or of $I(L)$ are such that $\bar{L} \leqslant \operatorname{Min}\left\{Z^{*}\left(W_{t}\right), L^{*}\left(M_{t}, W_{t}\right)\right\}$ where $\bar{L}$ is the equilibrium level of employment. If $\bar{L}>Z^{*}\left(W_{t}\right)$ then clearly the classical case prevails and the equilibrium is obtained at $Z *\left(W_{t}\right)$.

$$
\bar{L}=L^{*}\left(M_{t}, W_{t}\right)=Z^{*}\left(W_{t}\right)
$$

and

$$
K(\bar{L})=I(\bar{L})=0
$$

if and only if

$$
X^{*}\left(M_{t}, W_{t}\right)=f\left(Z^{*}\left(W_{t}\right)\right)-g
$$

and

$$
\begin{aligned}
& L^{*}\left(M_{t}, W_{t}\right)=Z^{*}\left(W_{t}\right) . \\
& L^{*}\left(M_{t}, W_{t}\right)<Z^{*}\left(W_{t}\right)
\end{aligned}
$$

and

$$
K\left(L^{*}\left(M_{t}, W_{t}\right)\right)=I\left(L^{*}\left(M_{\iota}, W_{t}\right)\right)=0
$$

if and only if

$$
X^{*}\left(M_{t}, W_{t}\right)=f\left(L^{*}\left(M_{t}, W_{t}\right)\right)-g
$$

and

$$
\begin{aligned}
& L^{*}\left(M_{t}, W_{t}\right)=f^{-1}\left(X^{*}\left(M_{t}, W_{t}\right)+g\right) . \\
& L^{*}\left(M_{t}, W_{t}\right)>Z^{*}\left(W_{t}\right)
\end{aligned}
$$

and

$$
K\left(Z^{*}\left(W_{t}\right)\right)=0>I\left(Z^{*}\left(W_{t}\right)\right)
$$

if and only if

$$
C_{u}\left(M_{t}, W_{t}, Z^{*}\left(W_{t}\right)\right)=f\left(Z^{*}\left(W_{t}\right)\right)-g
$$


and

$$
\begin{aligned}
& L^{*}\left(M_{i}, W_{t}\right)>Z^{*}\left(W_{t}\right) \\
& L^{*}\left(M_{t}, W_{t}\right)>Z^{*}\left(W_{t}\right)
\end{aligned}
$$

and

$$
K\left(Z^{*}\left(W_{t}\right)\right)>0=I\left(Z^{*}\left(W_{t}\right)\right)
$$

if and only if

$$
A_{x}\left(M_{t}, W_{t}, f\left(Z^{*}\left(W_{t}\right)\right)-g\right)=Z^{*}\left(W_{t}\right)
$$

and

$$
\begin{gathered}
X^{*}\left(M_{t}, W_{t}\right)>f\left(Z^{*}\left(W_{t}\right)\right)-g \\
\tilde{L}<L^{*}\left(M_{t}, W_{t}\right), \quad \tilde{L}<Z^{*}\left(W_{t}\right)
\end{gathered}
$$

and

$$
K(\tilde{L})=0>I(\tilde{L})
$$

if and only if

$$
C_{u}\left(M_{t}, W_{t}, \tilde{L}\right)=f(\tilde{L})-g
$$

and

$$
\begin{gathered}
\tilde{L}<L^{*}\left(M_{t}, W_{t}\right), \quad \tilde{L}<Z^{*}\left(W_{t}\right) . \\
\tilde{L}<L^{*}\left(M_{t}, W_{t}\right), \quad \tilde{L}<Z^{*}\left(W_{t}\right), \quad \text { and } \quad K(\tilde{L})>0=I(\tilde{L})
\end{gathered}
$$

if and only if

$$
A_{x}\left(M_{t}, W_{t}, f(\tilde{L})-g\right)=\tilde{L}
$$

and

$$
\begin{gathered}
X^{*}\left(M_{t}, W_{t}\right)>f(\tilde{L})-g . \\
K\left(Z^{*}\left(W_{t}\right)\right)>0 \quad \text { and } \quad I\left(Z^{*}\left(W_{t}\right)\right)<0
\end{gathered}
$$

if and only if

$$
C_{u}\left(M_{t}, W_{t}, Z^{*}\left(W_{t}\right)\right)>f\left(Z^{*}\left(W_{t}\right)\right)-g
$$

and

$$
A_{x}\left(M_{t}, W_{t}, f\left(Z^{*}\left(W_{t}\right)\right)-g\right)>Z^{*}\left(W_{t}\right)
$$

Due to the above result, the state space $\left(M_{t}, W_{t}\right)$ can now be divided into $642 / 37 / 2=4$ 
three mutually exclusive regions of Keynesian, classical, and inflationary disequilibria where the other four cases determine the boundaries of these regions. Some straightforward calculations yield the slopes for the three respective boundaries. Using (2) which determines the boundary between Keynesian and inflationary states, one obtains

$$
\left.\frac{d M_{t}}{d W_{t}}\right|_{(2)}=-\frac{\frac{\partial X^{*}}{\partial W_{t}}-f^{\prime} \frac{\partial L^{*}}{\partial W_{t}}}{\frac{\partial X^{*}}{\partial M_{t}}-f^{\prime} \frac{\partial L^{*}}{\partial M_{t}}},
$$

which may be positive, zero, or negative. Similarly for the boundary between Keynesian and classical states, which is determined by (3), one obtains

$$
\left.\frac{d W_{t}}{d M_{t}}\right|_{(3)}=-\frac{\frac{\partial C_{u}}{\partial M_{t}}}{\frac{\partial C_{u}}{\partial W_{t}}+\frac{\partial Z^{*}}{\partial W_{t}}\left(\frac{\partial C_{u}}{\partial L}-f^{\prime}\right)} .
$$

$f^{\prime}>\partial C_{u} / \partial L, \partial Z^{*} / \partial W_{t}<0$, combined with the other assumptions, determines a negative slope. Finally, from (4) one obtains for the boundary between classical and inflationary states

$$
\left.\frac{d W_{t}}{d M_{t}}\right|_{(4)}=-\frac{\frac{\partial A_{x}}{\partial M_{t}}}{\frac{\partial A_{x}}{\partial W_{t}}+\frac{\partial Z^{*}}{\partial W_{t}}\left(\frac{\partial A_{x}}{\partial X} f^{\prime}-1\right)},
$$

which has a positive slope using our assumptions. The associated diagrammatic representation of these properties (Fig. 3) corresponds to the one obtained by Barro and Grossman, to which we will also add the iso-employment-loci for the three different regions. Their slopes and orientation can be obtained from our assumptions in a straightforward manner. The three regions have been labeled $K, C$, and $I$, respectively. The iso-employment-loci are given for levels of employment $L_{1}<L_{2}<L_{3}$. Maximum employment is achieved at the Walrasian equilibrium WE.

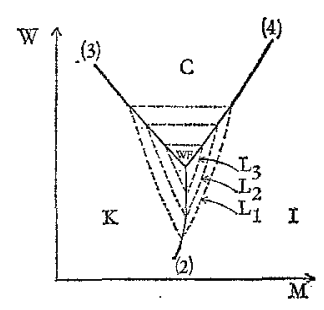

Frgure 3 


\section{The Dynamics of Disequilibrium Savings}

The dynamic behavior of the model embodies two distinct elements which play a different role in the determination of the time path. On the one hand, if disequilibrium states of the kind described persist over several periods prices and wages will eventually change. Little is known at present about how to model such a price and wage adjustment mechanism. On the other hand, even at fixed prices and wages, the savings behavior of consumers determines the natural dynamic link between any two successive periods which implies changes in money holdings in the economy. As long as these persist employment and output changes will occur from one period to another. Both phenomena price and savings adjustment would have to be considered in a general dynamic model. However, it seems important to analyze the savings adjustment separately since it indicates some relevant properties of the endogenous dynamic structure of the model. The first part of this section therefore analyzes the impact of savings on the dynamic development keeping prices and wages fixed. This does not mean, however, that we are not aware of the necessity of introducing price and wage changes as well. The second part, in which some real wage adjustment is introduced, presents two examples which can only serve as a general indication of some qualitative properties. Nevertheless we feel it is worthwhile to point out these properties.

In order to understand the dynamic behavior of the model some additional features which concern the role of the government have to be made more explicit. Since the government plays only the role of a passive consumer with a fixed consumption of $g$ the usual accounting identities of total spending on commodities and total income generated (i.e., profits plus wage income) imply that government consumption in any feasible state is equal to real profit plus real savings. Combined with the assumption that consumers receive no profit payments this is equivalent to the assumption that all profits are taxed and go to the government to finance its consumption. If profits are insufficient this implies deficit spending and money creation on the part of the government which, in turn, increases cash balances of consumers. Conversely, profits larger than government consumption decrease private money holdings which implies money destruction. Therefore all stationary states generate profits, i.e., taxes, exactly equal to government spending and therefore involve a balanced budget, a necessary condition for stationarity. The profit distribution scheme seems very special, but it captures the basic feature of a fixed government consumption plan under variable government receipts and its implications on the money holdings of the private sector. On the other hand, the qualitative properties of the model would remain unchanged if some part of the profits goes to consumers. For a model with the same features, see, e.g., Futia [9] and Malinvaud [13], for one which includes some distribution of profits, see Barro and Grossman [2]. 
It is clear from the previous remarks that the activities of the production sector do not depend on monetary phenomena, i.e., no money is accumulated in that sector. Moreover it is assumed that accumulation of capital is not possible since no investment activity is included. The model therefore preserves the short-run structure in spite of the fact that the dynamic development over several periods is considered.

From the structure of the model it is clear that only a particular choice of $M, W$, and of $g$ will result in zero savings at the Walrasian temporary equilibrium, thus making the pair $(M, W)$ a stationary point of the dynamic system. Hence, for an arbitrary but fixed $g$, which in our case has to be in line only with assumption (A), the Walrasian temporary equilibrium will not be stationary in general. Therefore, the dynamic analysis will not be concerned with the stability or instability of this particular equilibrium. The case of a stationary Walrasian temporary equilibrium is discussed extensively by Dehez and Jaskold Gabszewicz [5]. Stationary states in our analysis will be either of the Keynesian or of the inflationary type. Classical disequilibria will not arise by restricting the range of the real wage.

Letting $W$ remain constant at some level such that for alternative values of $M$ either Keynesian or inflationary states are obtained, the following two systems of equations determine the time path of real balances. If $\left(M_{t}, W\right)$ is Keynesian, then

$$
\begin{array}{r}
M_{t+1}-M_{t}+C_{u}\left(M_{t}, W, L_{t}\right)-W L_{t}=0, \\
L_{t}-f^{-1}\left(C_{u}\left(M_{t}, W, L_{t}\right)+g\right)=0 .
\end{array}
$$

If $\left(M_{t}, W\right)$ is inflationary, then

$$
\begin{array}{r}
M_{t+1}-M_{t}+Y_{t}-g-t A_{x}\left(M_{t}, W, Y_{t}-g\right)=0, \\
Y_{t}-f\left(A_{x}\left(M_{t}, W, Y_{t}-g\right)\right)=0 .
\end{array}
$$

Denoting actual savings under the Keynesian situation by $S_{u}\left(M_{t}, W\right)$ and under repressed inflation by $S_{x}\left(M_{t}, W\right)$, the loci of stationary values of $(M, W)$ can be obtained for the two different regions by some straightforward calculations. For any Keynesian situation one obtains

$$
\left.\frac{d S_{u}}{d M_{t}}\right|_{\mathbf{K}}=-\frac{\partial C_{u}}{\partial M_{t}} \cdot \frac{f^{\prime}-W}{f^{\prime}-\frac{\partial C_{u}}{\partial L}}
$$

and

$$
\left.\frac{d S_{u}}{d W}\right|_{\mathbb{M}_{i=\text { const }}}=\frac{L\left(f^{\prime}-\frac{\partial C_{u}}{\partial L}\right)-\frac{\partial C_{u}}{\partial W}\left(f^{\prime}-W\right)}{f^{\prime}-\frac{\partial C_{u}}{\partial L}} .
$$


The first term is negative. The numerator of the second expression is positive. The second term of the denominator will be small for high wages which makes the whole term positive, possibly negative for low wages. Hence,

$$
\left.\frac{d M_{t}}{d W}\right|_{S_{u}=0}=\frac{L\left(f^{\prime}-\frac{\partial C_{u}}{\partial L}\right)-\frac{\partial C_{u}}{\partial W}\left(f^{\prime}-W\right)}{\frac{\partial C_{u}}{\partial M_{t}}\left(f^{\prime}-W\right)}
$$

determines the slope of the locus of stationary points, which is positive for high wages, possibly negative for low wages.

For situations of repressed inflation one obtains in a similar fashion

$$
\left.\frac{d S_{x}}{d M_{t}}\right|_{\mathbf{I}}=-\frac{\frac{\partial A_{x}}{\partial M_{t}}\left(f^{\prime}-W\right)}{\left(1-f^{\prime} \frac{\partial A_{x}}{\partial X}\right)},
$$

which is positive, and

$$
\left.\frac{d S_{x}}{d W}\right|_{M_{M_{t}=\mathrm{const}}}=\frac{A_{x}\left(1-f^{\prime} \frac{\hat{\partial} A_{x}}{\partial X}\right)-\frac{\partial A_{x}}{\partial W}\left(f^{\prime}-W\right)}{1-f^{\prime} \frac{\partial A_{x}}{\partial X}},
$$

which is positive for high wages, possibly negative for low wages. Therefore,

$$
\left.\frac{d M_{t}}{d W}\right|_{S_{x}=0}=-\frac{A_{x}\left(1-f^{\prime} \frac{\partial A_{x}}{\partial X}\right)-\frac{\partial A_{x}}{\partial W}\left(f^{\prime}-W\right)}{-\frac{\partial A_{x}}{\partial M_{t}}\left(f^{\prime}-W\right)}
$$

which indicates a downward sloping locus for high wages, possibly upward sloping for low wages.

Combining these results in our phase diagram, one obtains the characterization given in Fig. 4. The diagram has been drawn for the case of positive

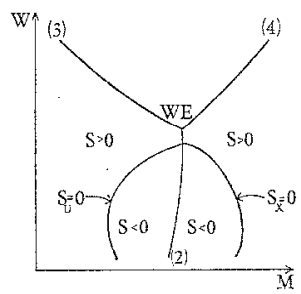

FigURE 4 
savings at the Walrasian temporary equilibrium. Some straightforward arguments show that any two stationary states of the Keynesian and of the repressed inflation type with the same wage rate generate the samc lcvel of employment.

The qualitative analysis done so far confirms some properties which one might have expected on intuitive grounds. If savings are positive, at the Walrasian temporary equilibrium, then a trajectory of $M$ with the "correct" real wage will pass through WE but eventually generating repressed inflation. Employment will rise as long as such a path is Keynesian, and it will fall as soon as it passes into inflationary states. Furthermore, high real balances will always be associated with states of repressed inflation. If they are high enough the rationing on the goods market will in all cases force consumers into additional savings, thus increasing real money balances even further. Given the underlying expectations this will create more inflationary pressure. All stationary states of repressed inflation are globally unstable.

A symmetric argument for stationary Keynesian states does not hold, except possibly for low real wages. The global stability of such states for a large range of real wages is in sharp contrast with the previous result. It indicates that for the fixed level of government consumption the system may get trapped in a stationary Keynesian state with a low level of employment. The comparative statics properties of the model indicate, however, that an increase in government consumption is a remedy to increase employment (see, for example, Malinvaud [13] or Hildenbrand and Hildenbrand [12]).

Not all properties of the actual dynamic development can be deduced from the previous qualitative analysis of the phase diagram. Let $F_{\mathrm{K}}\left(M_{t}, W\right)=$ $M_{t+1}$ and $F_{\mathrm{I}}\left(M_{t}, W\right)=M_{t+1}$ denote the two solutions of the two systems (K) and (I), respectively. Since

$$
\frac{\partial F}{\partial W}=\left.\frac{d S}{d W}\right|_{M_{t}=\text { const }}
$$

and

$$
\frac{\partial F}{\partial M_{t}}=\frac{d S}{d M_{t}} \mid+1
$$

we have

$$
\frac{\partial F_{\mathrm{I}}}{\partial M_{t}}>1 \quad \text { and } \quad \frac{\partial F_{\mathbf{K}}}{\partial M_{t}}<1
$$

since

$$
\left.\frac{d S_{x}}{d M_{t}}\right|_{\mathrm{I}}>0 \quad \text { and }\left.\quad \frac{d S_{u}}{d M_{t}}\right|_{\mathrm{K}}<0
$$


Assuming for the moment that

$$
\left.\frac{d S_{u}}{d M_{t}}\right|_{\mathrm{x}}>-1
$$

one obtains a family of upward sloping functions, one for each value of $W$ (see Fig. 5). Using these, the dynamic development can be deduced directly as being monotonically convergent to a Keynesian situation for all initial states $M_{0}$ not too large. For large $M_{0}$, the system diverges monotonically. One converging path for $W=W_{2}$ has been indicated.

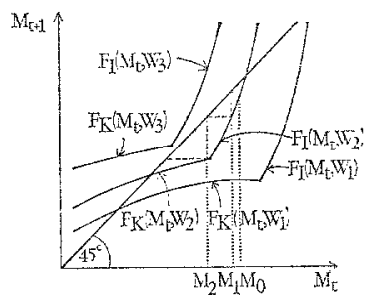

FIGURE 5

Closer examination of the total savings effect of real balances under Keynesian unemployment $d S_{u} /\left.d M_{t}\right|_{\mathrm{K}}$ shows that none of the assumptions made so far guarantees that it will be greater than minus one. Hence

$$
\frac{d S_{u}}{d M_{t}}=-\frac{\partial C_{u}}{\partial M_{t}} \cdot \frac{f^{\prime}-W}{f^{\prime}-\partial C_{u} / \partial L}
$$

will be less than minus one if

$$
\frac{\partial C_{u}}{\partial M_{t}} \geqslant 1 \quad \text { and } \quad \frac{\partial C_{u}}{\partial L} \geqslant W
$$

with one strict inequality. The first condition simply implies that on the aggregate level future consumption (i.e., final money holdings) is an inferior good. The second indicates an elasticity of consumption with respect to employment which is greater than one. Both conditions are related to a strong preference of present consumption over future consumption which induces more than a proportionate decrease in savings with respect to real balances. If this case occurs then

$$
\frac{\partial F_{\mathrm{K}}}{\partial M_{t}}<0
$$

and the associated dynamic development will follow a cyclical time path in 
the Keynesian region (see Fig. 6). Hence any convergent path will ultimately cycle in the Keynesian region inducing a general employment and output cycle. For extreme cases of inferiority which imply a savings effect of $\left.\left(d S_{u} / d M_{t}\right)\right|_{\mathrm{K}}<-2$ the system will be cyclically divergent.

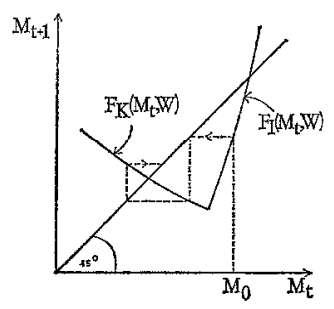

FIGURE 6

\section{Some Remarks on Disequilibrium Price Adjustment}

The previous section clearly indicates that the dynamic properties of this simple macroeconomic model are typically not of the kind which is usually assumed or deduced in the normal multiplier theory. Convergence, though monotonic, may lead to low levels of employment if savings are negative and if prices and wages are rigid for some time. Cyclical behavior may be an outcome of consumers' strong preference for present consumption independent of any lag or adjustment structure which is usually taken to be the sole origin of such dynamic properties. If such elements were introduced here it seems clear that they would increase the possibility for cycles rather than reduce it.

An interesting question which remains and which can be treated in a simple manner within the scope of this model is whether a price adjustment mechanism of the Walrasian type will increse or reduce the stability properties of this model. This possibility of changes in prices and wages is in any case imposed on any such model since the extreme short run clearly ends and induces such changes if more than a few periods are considered in the analysis. Some preliminary attempts toward a general theory of price setting behavior have been made recently (see, e.g., Benassy [3] and Grandmont and Laroque [10]). However, they are far from a general theoretical approach which could be applied in the present context. We will therefore follow the usual ad hoc assumption that prices are governed by excess demand. Within the framework here this leads to two alternative regimes which show strong qualitative implications for the dynamic behavior of this model.

If prices and wages adjust according to excess demand in the two regions of general excess supply and of general excess demand then prices and wages 
will move in the same direction. Therefore the real wage may increase or decrease depending on the specific adjustment process. Since the real wage is the crucial determining factor of consumption behavior apart from real balances the change in the real wage plays an important role for the dynamic development of the system. The remainder of this section presents two examples of a price and wage adjustment mechanism which preserves the sign of the change of real wages in the two alternative regions. This yields two different regimes. Such an analysis can be carried out in purely qualitative terms using the elements of the previous more precise analysis in spite of the fact that all price changes have an impact on real balances.

The first regime takes a more classical viewpoint asserting that at disequilibrium states with unemployment real wages are too high. Wages fall faster than prices whenever Keynesian disequilibrium occurs. As a counterpart it is assumed that wages rise faster than prices under excess demand, so that the real wage rises in the region of repressed inflation.

The second regime is the converse of the first one which may be justified using Keynesian arguments. Wages may be rigid downward so that prices fall faster. This increase of real wages in situations of unemployment will induce a multiplier effect of increasing consumption expenditures which is designed to increase labor demand and production. Conversely, in situations of repressed inflation prices rise faster than wages, so that an increase will reduce demand pressures primarily on the commodity market.

Figure 7 indicates the dynamic behavior for the first regime. It is immediately apparent that the instability of inflationary states with positive savings

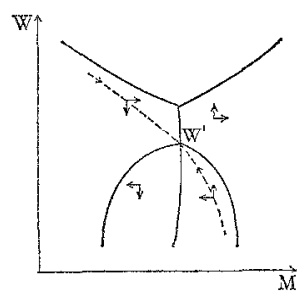

Figure 7

is drastically increased and the divergence from $W^{\prime}$ is faster than at fixed prices leading to lower and lower levels of employment. In the Keynesian region with negative savings the stability of stationary equilibria is destroyed. All successive states will show decreasing levels of employment. For the other two regions savings and wage effects may lead on a knife edge path to the stationary state $W^{\prime}$. All other paths will cross over into one of the other two regions, however, and will diverge eventually.

Figure 8 analyzes the effects of the second regime. It indicates that the 
global instability of the previous case is drastically reduced. Many paths, if they are diverging, will be cyclical. On the other hand, all paths starting with negative savings will tend to be cyclical. In general, one can conclude that this regime will typically show nonmonotonic behavior.

The analysis of this final section is clearly not a rigorous treatment of wage-price adjustments in disequilibrium. The intention is simply to express a warning against any simple ad hoc adjustment mechanism which takes into

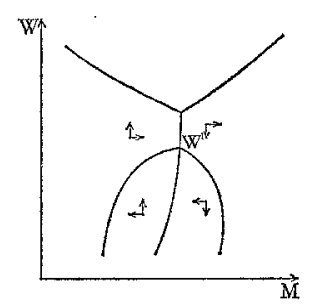

FIGURE 8

account only the particular disequilibrium state which has been obtained. Much more information and some fine tuning are required to construct an adjustment mechanism which results in a stable possibly noncyclical path to high levels of employment.

\section{ConCluding RemarKs}

The model ignores many important aspects which, according to our present understanding of such systems, have an important impact on the dynamic behavior. The most important of these clearly is the elimination of distributional effects of the underlying rationing scheme on savings and on effective demands and supplies. A second very important restriction is the asymmetrical treatment of consumers and producers. While consumers are placed in a proper intertemporal environment to describe savings behavior, the production sector is represented by an atemporal simple macroeconomic production function. No monetary considerations enter into the production decisions.

The dynamic analysis consistently ignores any long run properties of the model. It concentrates on the typical "medium" run development which should be taken as that number of periods after which a revision of exogenous control variables or other parameters occurs if the dynamic process leads to undesirable states. How such changes occur and/or how an economic policy should be designed constitutes a wide area of new research. 


\section{ACKNOWLEDGMENTS}

I an indebted to Pierre Dehez for valuable comments and criticisin. Financial suppori of the Fonds National de la Recherche Scientifique is greatfully acknowledged. Part of this research was done while the author was visiting the University of Konstanz, Germany.

\section{REFERENCES}

1. K. J. ARrow AND F. H. HAHN, "General Competitive Analysis"" Holden-Day, San Francisco, 1971.

2. R. J. Barro and H. I. Grossman, "Money, Employment and Inflation," Cambridge Univ. Press, London/New York, 1976.

3. J. P. Benassy, The disequilibrium approach to monopolistic price setting and general monopolistic equilibrium, Rev. Econ. Studies 43 (1976), 69-81.

4. R. W. ClowER, The Keynesian counterrevolution: A theoretical appraisal, in "The Theory of Interest Rates" (F. H. Hahn and F. R. P. Brechling, Eds.), pp. 104-115, Macnillan \& Co., London, 1965.

5. P. Dehez And J. JASKold GABSZEWICZ, "On the Convergence of Sequences of Disequilibria," CORE Discussion Paper No. 7701, 1977.

6. A. Drxrr, Public finance in a Keynesian temporary Equilibrium, $J$. Econ. Theory 12 (1976), 242-258.

7. A. Dixir, "The Balance of Trade in a Model of Temporary Equilibrium with Rationing," University of Warwick Working Paper No. 98, 1976.

8. J. H. DrèzE, Existence of an exchange equilibrium under price rigidities, Internat. Econ. Rev. 16 (1975), 301-320.

9. C. A. FUTiA, Excess supply equilibria, J. Econ. Theory 14 (1977), 200-220.

10. J. M. Grandmont and G. Laroque, On temporary Keynesian equilibria, Rev. Econ. Studies 43 (1976), 53-67.

11. J. M. GRANDMONT AND Y. YOUNÈs, On the role of money and the existence of a monetary equilibrium, Rev. Econ. Studies 39 (1972), 355-372.

12. K. Hudengrand and W. Hudengrand, "On Malinvaud's 'Reconsideration of the Theory of Unemployement", University of Bonn (mimeographed), 1976.

13. E. Malinvaud, "The Theory of Unemployment Reconsidered," Basil Blackwell, Oxford, 1977.

14. H. R. VARIAN, On persistent disequilibrium, J. Econ. Theory $10(1975), 210-228$. 